\title{
Commentary: Mechanical ventilation: A toxic asset
}

\author{
David P. Bichell, MD
}

\footnotetext{
From the Department of Cardiac Surgery, Monroe Carell, Jr. Children's Hospital, Vanderbilt University Medical Center, Nashville, Tenn.

Disclosures: Author has nothing to disclose with regard to commercial support.

Received for publication Nov 10, 2018; accepted for publication Nov 12, 2018; available ahead of print Jan 14, 2019.

Address for reprints: David P. Bichell, MD, Pediatric Cardiac Surgery, William S. Stoney, Jr. Chair in Cardiac Surgery Monroe Carell, Jr. Children's Hospital Vanderbilt University Medical Center, 5247 Doctors' Office Tower, 2200 Children's Way, Nashville, TN37232-9292 (E-mail: david.bichell@ vanderbilt.edu).

J Thorac Cardiovasc Surg 2019;157:1599-600

$0022-5223 / \$ 36.00$

Copyright (C) 2018 by The American Association for Thoracic Surgery

https://doi.org/10.1016/j.jtcvs.2018.11.039
}

Disuse muscle atrophy, delirium, opioid addiction, benzodiazepine dependence, agitation, antibiotic-resistant infection, and microbiome derangement are among compounding iatrogenic expenses that start accruing, like debt on a high-interest loan, on admission to the postoperative intensive care unit (ICU). Recognizing the rapidly compounding dangers of ICU care, an "ICU liberation" philosophy is gaining traction in adult and pediatric settings, with coordinated attention to reducing sedation, performing early extubation, and encouraging mobility, aiming to pre-empt the cascade of iatrogenic complications that derails recovery for patients in the ICU. ${ }^{1}$

As little as 18 hours of mechanical ventilation results in muscle cell proteolysis and diaphragmatic atrophy in an animal model. ${ }^{2}$ In human subjects, 18 to 69 hours of mechanical ventilation already results in a loss of $>50 \%$ of cross-sectional area of fast- and slow-twitch diaphragmatic muscle fibers. ${ }^{3}$ The process certainly begins earlier than 18 hours and no doubt consequentially affects neonates with single-ventricle physiology, who arrive with an already-slim tolerance for insult. Within a matter of hours, the ventilator, an essential, surgery-enabling asset, begins turning into a toxic asset.

The Society of Thoracic Surgeons multi-institution congenital data show that centers with a high rate of early extubation are centers associated with shorter postoperative lengths of stay. ${ }^{4}$ Experience is growing to show that an immediate postoperative extubation of neonates after cardiac surgery may reduce hospital length of stay and cost, even compared with those extubated in the subsequent 24 hours. $^{5,6}$

Barriers to early extubation include uncoordinated, siloed care, staffing pressures that promote delays in extubation by attention-divided ICU physicians, and analgesia that overshoots the goal of awake comfort. ${ }^{7}$ The cascade begins as temporizing anxiolytics, then analgesics, paralytics, and delay, all tossed, like so many banana peels, onto the path across an already-slippery slope. comfort).

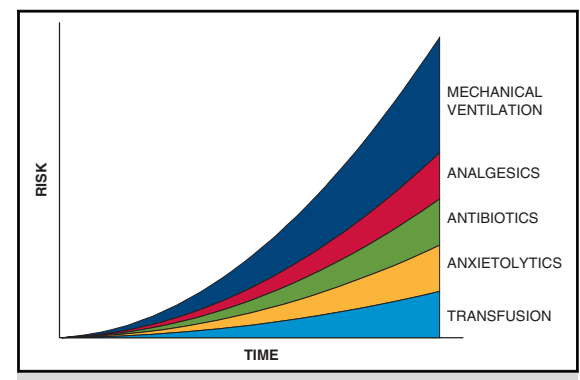

Postoperative risks compound with the advance of time on mechanical ventilation.

Central Message

Every hour of postoperative mechanical ventilation supports compounding iatrogenic risk. Organized mitigation of early risk supports immediate extubation after complex neonatal heart surgery.

See Article page 1591.

Varghese and colleagues have previously published an impressive series showing success at the immediate extubation of $30 \%$ of neonates after cardiac surgery, and in the current issue of the Journal, the same authors carry that concept further to include the immediate extubation of Norwoodsthe most vulnerable of postoperative patients. 5,8 This retrospective feasibility study is an inspired example of the collaborative approach needed to deprive the demons of chaos from gripping the first hours of postoperative care and launching a course of compounding risk. The impressive achievement of immediate extubation after the Norwood is testament to an extraordinary coordinated effort organized between anesthesiology (planned early reversal, minimal blood product transfusion), perfusion (minimized and balanced priming volume), surgery (uninterrupted splanchnic perfusion, avoidance of hypothermia, meticulous hemostasis), and critical care (attentive management of the extubated patient, awake

Only mission-driven, coordinated attention at each step of the early hospital course can minimize oxidative stress, preserve autoregulation, minimize disruption of cellular homeostasis, and support organ recovery to allow successful immediate extubation after complex neonatal heart surgery. Varghese and colleagues are leading the way to raise expectations for early extubation after neonatal surgery, but more importantly, their work leads a standard for interdisciplinary collaboration that can thwart the march of some 
early compounding physiologic insults that were formerly regarded as inevitable.

\section{References}

1. Ely EW. The ABCDEF bundle: science and philosophy of how ICU liberation serves patients and families. Crit Care Med. 2017;45:321-30.

2. Shanely RA, Zergeroglu MA, Lennon SL, Sugiura T, Yimlamai T, Enns D, et al. Mechanical ventilation-induced diaphragmatic atrophy is associated with oxidative injury and increased proteolytic activity. Am J Respir Crit Care Med. 2002; 166:1369-74.

3. Levine S, Nguyen T, Taylor N, Friscia ME, Budak MT, Rothenberg P, et al. Rapid disuse atrophy of diaphragm fibers in mechanically ventilated humans. $N$ Engl J Med. 2008;358:1327-35.

4. Mahle WT, Jacobs JP, Jacobs ML, Kim S, Kirshbom PM, Pasquali SK, et al. Early extubation after repair of tetralogy of Fallot and the Fontan procedure: an analysis of the Society of Thoracic Surgeons congenital heart surgery database. Ann Thorac Surg. 2016;102:850-8.

5. Varghese J, Kutty S, Abdullah I, Hall S, Shostrom V, Hammel JM. Preoperative and intraoperative predictive factors of immediate extubation after neonatal cardiac surgery. Ann Thorac Surg. 2016;102:1588-95.

6. Vricella LA, Dearani JA, Gundry SR, Razzouk AJ, Brauer SD, Bailey LL. Ultra fast track in elective congenital cardiac surgery. Ann Thorac Surg. 2000;69: 865-71.

7. Krawiec C, Carl D, Stetter C, Kong L, Ceneviva GD, Thomas NJ. Challenges with implementation of a respiratory therapist-driven protocol of spontaneous breathing trials in the pediatric ICU. Respir Care. 2017;62: 1233-40.

8. Varghese J, Hammel JM, Ibrahimiye A, Siecke R, Moukagnae K, Kutty S. Outcomes related to immediate extubation after stage 1 Norwood palliation for hypoplastic left heart syndrome. J Thorac Cardiovasc Surg. 2019;157: 1591-8. 